\title{
Modelling the Terroir of the Douro Demarcated Region, Portugal
}

\author{
Helder Fraga ${ }^{1}$, Ricardo Costa $^{1}$ and João Santos ${ }^{1}$ \\ ${ }^{1}$ Centre for the Research and Technology of Agro-Environmental and Biological Sciences, CITAB, Universidade de \\ Trás-os-Montes e Alto Douro, UTAD, 5000-801 Vila Real, Portugal, hfraga@utad.pt
}

\begin{abstract}
The Douro Demarcated Region (DDR) is one of the main winemaking regions in Portugal. Viticulture is tied to the Douro region, having a strong impact on the local economy. This mountainous region, characterized by the slopes of the Douro Valley, provides a vast range of environmental characteristics for winegrapes. Different climatic conditions, soil characteristics, topography, varieties and practices comprise the Douro terroirs, resulting in the uniqueness of the wines produced. In the current study, an assessment of the homogeneous viticultural zones is proposed for the Douro, by integrating different terroir elements (thermal, hydric, soils, topography and vegetation), using state-of-the-art very-high resolution datasets (1-km) and a large number of variables. A multivariate zoning was carried out using a principal component analysis (PCA) and a subsequent clustering. A geospatial assessment of the terroir elements was also performed separately for each sub-region in the DDR. The connections of the different terroirs prevailing at a given location were also innovatively assessed. This zoning may promote a more appropriate selection of vineyard sites, the selection of more locally-adapted varieties and rootstocks and the adoption of appropriate viticultural practices. The present study may be a standard methodology that can be applied to other winemaking regions worldwide.
\end{abstract}

\section{Introduction}

Detecting the unique characteristics within a given viticultural region is key to assessing the winemaking suitability and potential. This zoning assesses the most relevant viticultural characteristics in each winegrowing region, providing a basis for strategic vintage planning (Costantini et al. 2016). The regional climate, soil properties, topography, varieties (biodiversity) and management practices of any given winemaking regions are usually described by the terroir concept (OIV 2010).

Climate is the main driver for winegrape development and growth (Keller 2010). Temperature and water availability influence winegrape yields and are responsible for a balanced grape ripening (Fraga et al. 2015). Soil is another key terroir element, crucial for water and nutrients, which influences grape quality attributes (Morlat and Jacquet 2003). The topographic elements are another important factor that influences viticultural characteristics of a given region, such aselevation, slope and solar exposure (Yau et al. 2013). Additionally, the vegetation: winegrape cultivars; cover crops and management practices are also important terroir elements (Böhm 2010).
The Douro Demarcated Region (DDR) is famous for its Port Wine and other high-quality wines. The DDR encompasses over 250,000ha in the Douro valley (Figure 1b). It is one of the most important winemaking regions in Portugal, accounting for approximately $20 \%$ of the country's vineyard area and wine production (IVV 2015). 


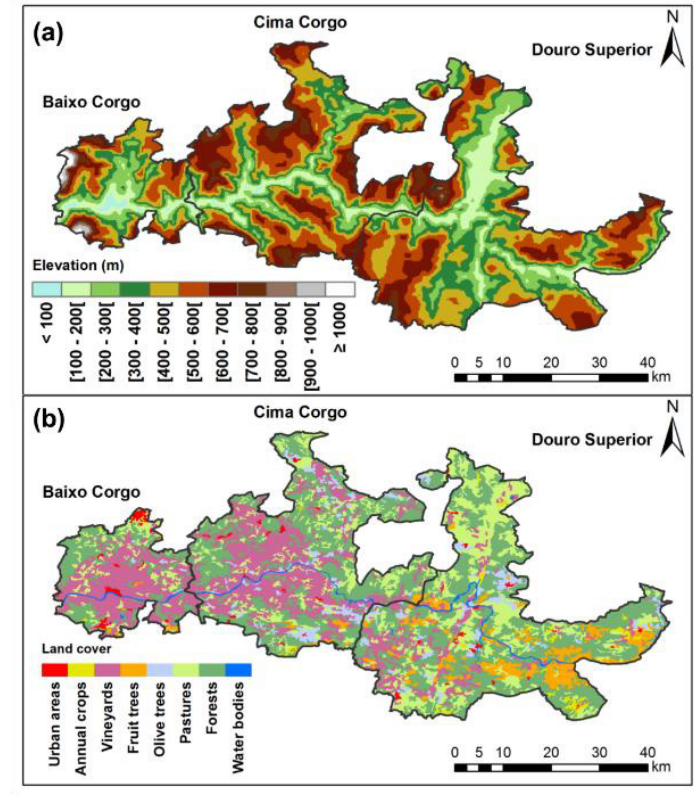

Figure 1 - (a) Digital elevation model of the Douro Demarcated Region (DDR). (b) Land cover classification in the DDR, according to the CORINE land cover map. The three sub-regions of the DDR, Baixo Corgo (BC), Cima Corgo (CC) and Douro Superior (DS), are also outlined.

Given the distinctness of the DDR, it is important to define its terroir characteristics in a thorough integrated approach. Given the unique Mediterranean-type climatic characteristics and the complex orography of the DDR, very high resolution zoning data is required. Similar terroir conditions across the regions should produce wines with similar characteristics. The present study aims to develop a multivariate zoning approach, through a holistic integration of the main terroir elements, herein illustratively applied to the DDR. A similar methodology can be conducted in other viticultural regions worldwide.

\section{Material and Methods}

\subsection{Terroir elements}

In the current study, five terroir elements were considered: (i) thermal conditions; (ii) hydric conditions, (iii) soils, (iv) topography and (v) vegetation dynamics.

To assess (i) and (ii) terroir elements, highresolution datasets, produced by the WorldClim project (Hijmans et al. 2005) at ca. $1 \mathrm{~km}$ spatial resolution, were used. For the thermal conditions, the following variables were assessed: annual, seasonal (DJF: December-January-February, MAM: March-AprilMay, JJA: June-July-August, SON: SeptemberOctober-November) and growing season (AprilOctober) minimum, maximum and mean temperatures; Cool night index (CI; Tonietto 1999) from Fraga et al. (2014); Growing degree-day (GDD; Winkler 1974) from Fraga et al. (2014); Thermicity index (TI; RivasMartínez and Rivas-Saenz 2011) from Costa et al. (2017). For the hydric conditions, the following variables were selected: annual, seasonal (DJF, MAM, JJA, SON) and growing season (April-October) precipitation totals; Aridity index (AI; Rivas-Martínez and Rivas-Saenz 2011) from Costa et al. (2017); Dryness index (DI; Tonietto and Carbonneau 2004) from Fraga et al. (2014).

Soil properties were obtained from the Harmonized World Soil Database (HWSD; FAO/IIASA/ISRIC/ISSCAS/JRC 2012). HWSD soil properties were originally mapped at a 1:1,000,000 scale and are available at a resolution of $\sim 1 \mathrm{~km}$. The selected variables were: Bulk density $\left(\mathrm{kg} \mathrm{dm}^{-3}\right)$; Clay content $(\%)$; $\mathrm{pH}(-\log (\mathrm{H}+))$; Salinity $\left(\mathrm{dS} \mathrm{m}^{-1}\right)$; Sand content (\%); Gravel content (\%); Silt content $(\%)$; Organic content $(\%)$; Total exchangeable bases $(\mathrm{cmol}$ $\mathrm{kg}^{-1}$ ) and Sodicity (\%). Additionally, water table depth, retrieved from Fan et al. (2013), was also included in the analysis.

A fourth set of variables was chosen to characterize the topography of the DDR, including elevation (m), slope $\left(^{\circ}\right)$ and solar exposure (number of hours of sun, excluding clouds). Elevation was retrieved from a digital elevation model, DEM (GTOPO30). Slope and solar exposure (photoperiod) were calculated from the DEM dataset using geographical information systems ArcGIS (version 10.3.1) Spatial Analyst Tool.

A fifth set of variables was included to take into account the effect of vegetation growth and winegrape phenology. The Normalized Difference Vegetation Index (NDVI) was used for the analysis of the vegetative growth. NDVI takes into account the difference between near-infrared and red reflectances, providing a measure of vegetation greenness, where higher NDVI corresponds to higher vegetation greenness (Huete et al. 2002). NDVI from the Moderate Resolution Imaging Spectroradiometer (MODIS) is obtained from the National Aeronautics and Space Administration (NASA) Land Processes Distributed Active Archive Center (LP DAAC; https://lpdaac.usgs.gov/). Two tiles covering all of Portugal (h17v04, h17v05) are retrieved, at a $1 \mathrm{~km}$ spatial resolution and on a 16-day temporal resolution, from 2000 to 2015. Furthermore, a set of maps containing the Julian dates of the main winegrape phenological timings (budburst, flowering, veraison and harvest) were also included as variables in the vegetation dynamics set. This data, which has been previously validated, was obtained from Fraga et al. (2016a).

\subsection{Principal component analysis and clustering methodology}

The delineation of homogeneous zones in the DDR was carried out using a principal component analysis (PCA) and a subsequent $k$-means clustering methodology, using MATLAB (version R2017a). Variables of each of the 5 terroir elements (thermal, hydric, soils, topography and vegetation) were first normalized by the corresponding mean prior to PCA, as variables have different physical units, also warranting equal weighting in clustering. PCA was used herein as a method to reduce the number of variables (over 40 variables for all terroir elements) to retain for subsequent clustering $(k$ means on the subspace of the leading orthogonal 
modes). After a preliminary sensitivity analysis, the leading two components (PC1 and PC2) of each terroir element were retained, in all cases cumulatively explaining much of the variance. The number of resulting clusters was tested and four clusters were eventually selected for each element. Finally, the resulting clusters were mapped, corresponding to the viticultural terroirs in the DDR at ca. $1 \mathrm{~km}$ spatial resolution (total of $39101 \mathrm{~km}$ grid-cells).

\subsection{Relationships between the different terroir elements} The highest occurrence between clusters of different terroir elements at the same $1 \mathrm{~km}$ grid-cell is determined. This assessment was done separately for each of the sub-regions within the DDR (Baixo Corgo: BC; Cima Corgo: CC and Douro Superior: DS). The frequencies of occurrence of each clusters/terroir element were also assessed separately by each land cover class, using the CORINE land cover classification (EEA 2002) shown in Figure 1b.

\section{Results}

\subsection{Clustering approach}

Cumulatively, the explained variance of the first two PCs was over $93 \%$ for the thermal, hydric and vegetation groups and over $66 \%$ for the soil and topography groups. The first principal component represents more than $90 \%$ of the total variance for the thermal and hydric groups, while the second component represents much lower variance $3.5 \%$ and $1.5 \%$, respectively). For the other three terroir elements, the first PC, while still explaining large fractions of variance, showed comparatively low values (soil: $44.9 \%$; topography; $34.7 \%$; vegetation: $62.8 \%$ ), while the second PC now acquires higher relative relevance. For these terroir elements, the spatial organization of the region in near-homogeneous areas is much less marked than for the thermal, hydric and vegetation groups, thus explaining the overall lower fractions of represented variance.

A description of the four resulting clusters of each terroir element is provided in Table I. While the description of the thermal, hydric, topography and vegetation clusters are self-explanatory, the soil clusters correspond to the underlining 'soil unit name' from FAO (Food and Agriculture Organization of the United Nations) in the original soil dataset (FAO/IIASA/ISRIC/ISSCAS/JRC 2012). Therefore, the nomenclature used in the HSWD was kept. Regarding the thermal clusters (Fig.2a), a clear distinction is evident in all the corresponding variables, with minimum temperature in the winter playing a key role for the zoning. Also for the hydric conditions (Figure 2c), a strong variable differentiation is apparent, being DI the leading variable. For the soil clustering (Figure $2 \mathrm{e}$ ), some of the base variables have a more decisive role in zoning. Luvisols have higher gravel levels, Humic Cambisols have higher total exchangeable bases, Eutric/Dystric Cambisols show sand content and higher exchangeable sodium and Dystric Regosols have higher levels of organic matter. Regarding topography (Figure
$2 \mathrm{~g}$ ), the description of the clusters is directly based on the weight of each of the three base variables. For the vegetation clustering (Figure 2i), NDVI acquires a more important role for zoning, particularly its summer values.

Table I - Description of the clusters for each terroir element.

\begin{tabular}{|c|c|c|c|c|}
\hline \multirow{2}{*}{$\begin{array}{l}\text { Terroir } \\
\text { element } \\
\text { S }\end{array}$} & \multicolumn{4}{|c|}{ Clusters } \\
\hline & 1 & 2 & 3 & 4 \\
\hline $\begin{array}{l}\text { Therma } \\
\text { l }\end{array}$ & Cool & $\begin{array}{l}\text { Mode } \\
\text { rate } \\
\text { cool }\end{array}$ & $\begin{array}{l}\text { Moderate } \\
\text { warm }\end{array}$ & Warm \\
\hline Hydric & Wet & $\begin{array}{l}\text { Mode } \\
\text { rate } \\
\text { wet }\end{array}$ & $\begin{array}{l}\text { Moderate } \\
\text { dry }\end{array}$ & Dry \\
\hline Soil & Luvisol & $\begin{array}{l}\text { Humi } \\
\text { c } \\
\text { cambi } \\
\text { sol }\end{array}$ & $\begin{array}{c}\text { Eutric/D } \\
\text { ystric } \\
\text { cambisol }\end{array}$ & $\begin{array}{l}\text { Dystric } \\
\text { regosol }\end{array}$ \\
\hline $\begin{array}{l}\text { Topogr } \\
\text { aphy }\end{array}$ & $\begin{array}{c}\text { High } \\
\text { elev. } \\
\text { Low solar } \\
\text { exp. }\end{array}$ & $\begin{array}{l}\text { High } \\
\text { elev. } \\
\text { Low } \\
\text { slopes }\end{array}$ & $\begin{array}{l}\text { Low } \\
\text { elev. } \\
\text { High } \\
\text { slopes }\end{array}$ & $\begin{array}{c}\text { Low elev. } \\
\text { High } \\
\text { solar exp. }\end{array}$ \\
\hline $\begin{array}{l}\text { Vegetati } \\
\text { on }\end{array}$ & $\begin{array}{l}\text { Early } \\
\text { phen. } \\
\text { High } \\
\text { green. }\end{array}$ & $\begin{array}{l}\text { Early } \\
\text { phen. } \\
\text { Low } \\
\text { green. }\end{array}$ & $\begin{array}{l}\text { Late } \\
\text { phen. } \\
\text { Low } \\
\text { green. }\end{array}$ & $\begin{array}{l}\text { Late } \\
\text { phen. } \\
\text { High } \\
\text { green. }\end{array}$ \\
\hline
\end{tabular}




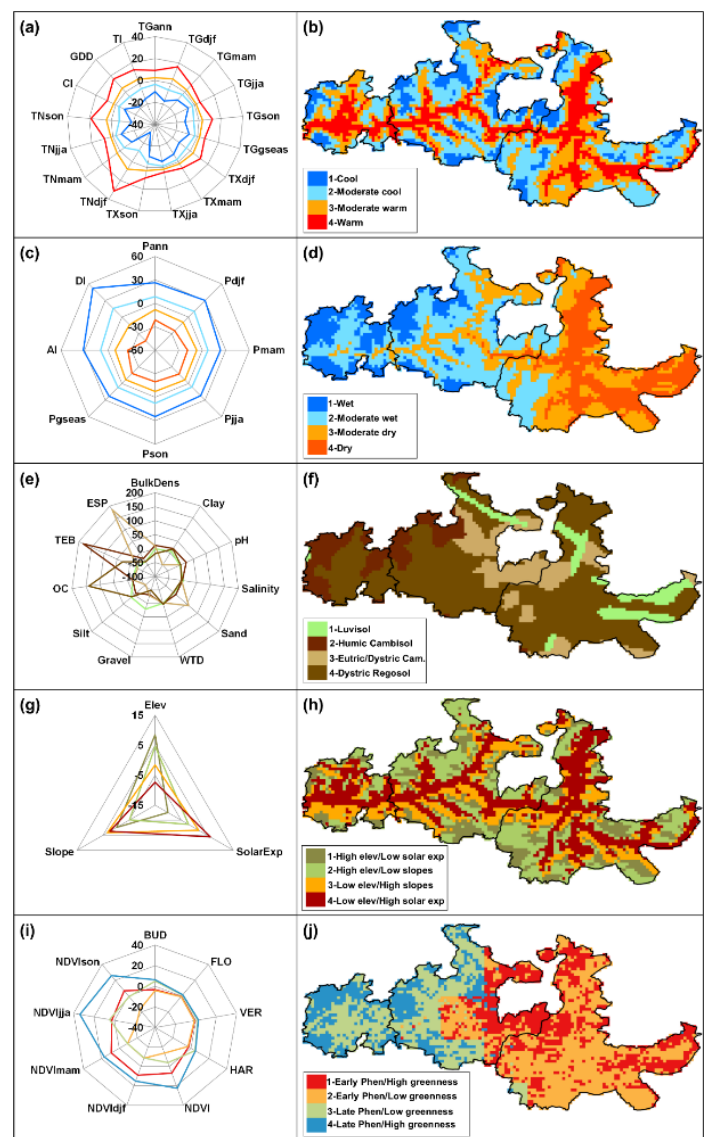

Figure 2 - Radar chart with the normalized values of the variables used in the clustering methodology: $(a, b)$ thermal; $(c, d)$ hydric; $(e, f)$ soils; (g, h) topography; (i, j) vegetation dynamics. Geographical representation of the clusters of each of the five terroir elements in the Douro Demarcated Region.

\subsection{Spatial homogeneity in the DDR}

After processing data from each of the terroir elements, a preliminary zoning of the DDR was achieved (Figure 2). Different homogeneous areas were established for each of the five terroir elements. The cooler (thermal cluster 1; henceforth Thermal-1) and moderate cooler zones (Thermal-2) are located in the outer/higher elevation areas of the DDR, while the moderate warm (Thermal-3) and warm (Thermal-4) zones are located in the inner/lower elevation areas (Figure 2b). For the whole DDR, the cluster with the highest frequency is Thermal-2, followed by Thermal-3 (Table II). The DDR is primarily characterized by moderately wet/wet (Hydric-2/Hydric-1) conditions in the western and central areas $(\mathrm{BC}$ and $\mathrm{CC})$, and moderately dry/dry (Hydric-3/Hydric-4) conditions in the east (DS) (Figure 2d). The Hydric-2 cluster has the highest occurrence (34\%; Table II). Regarding the soils of the DDR (Figure 2f), most of the region corresponds to the Soil-3 cluster: Dystric Regosols (63\%), while other clusters occur significantly less. Concerning topography, there is a strong association between high elevations, lower solar exposures and lower slopes (Topography-1 and -2, respectively) and between low elevations, high solar exposures and high slopes (Topography-3 and -4, respectively). The predominant cluster in the DDR is
Topography-4 (33\%) (Table II). For the vegetation clusters, a clear distinction between early phenology (Vegetation-1 and -2), in the eastern areas, and late phenology (Vegetation-3 and -4), in the west, is apparent. Higher greenness tends to occur in the higher elevation outer areas, while low greenness occurs in the inner areas of the DDR. The predominant cluster is Vegetation-2: early phenology and low greenness. The corresponding full dataset of these terroir classes is available as Supporting Information (S1 Appendix) so as to potentiate their application by researchers, decision-makers and stakeholders of the DDR winemaking sector.

Table II - Percentage of each cluster occurrence in the Douro Demarcated Region (DDR). Grey shaded values indicate the highest cluster occurrence for each class.

\begin{tabular}{lcccc}
\hline \multirow{2}{*}{$\begin{array}{l}\text { Terroir } \\
\text { elements }\end{array}$} & \multicolumn{4}{c}{ Clusters } \\
\cline { 2 - 5 } & $\mathbf{1}$ & $\mathbf{2}$ & $\mathbf{3}$ & $\mathbf{4}$ \\
\hline Thermal & $15 \%$ & $\mathbf{3 3 \%}$ & $30 \%$ & $22 \%$ \\
Hydric & $15 \%$ & $\mathbf{3 4 \%}$ & $29 \%$ & $22 \%$ \\
Soil & $9 \%$ & $12 \%$ & $16 \%$ & $\mathbf{6 3} \%$ \\
Topography & $18 \%$ & $28 \%$ & $21 \%$ & $\mathbf{3 3 \%}$ \\
Vegetation & $26 \%$ & $\mathbf{3 5 \%}$ & $22 \%$ & $17 \%$ \\
\hline
\end{tabular}

\subsection{Integrated sub-regional terroir assessment}

The relationships between clusters of the different terroir elements was also performed on a sub-regional level (for $\mathrm{BC}, \mathrm{CC}$ and $\mathrm{DS}$ ). The highest association between clusters is shown in Figure 3. In all sub-regions Dystric Regosols dominate the associations between soils and other terroir elements. For the BC sub-region (Figure 3a), the moderately cool and the wet areas are strongly associated. Warm areas are associated with low elevations/high solar exposures and late phenology/low greenness. Wet areas are also tied to late phenology/high greenness and humic cambisols. In this sub-region, moderate wet areas are associated with low elevations/high solar exposures. In the CC sub-region, moderate cool and moderate wet areas are highly associated, being also connected to high elevation areas/low slopes and late phenology/low greenness. In the DS sub-region, moderate warm areas show links to early phenology/low greenness, while warm dry areas with low elevations and high solar exposures largely overlap. 


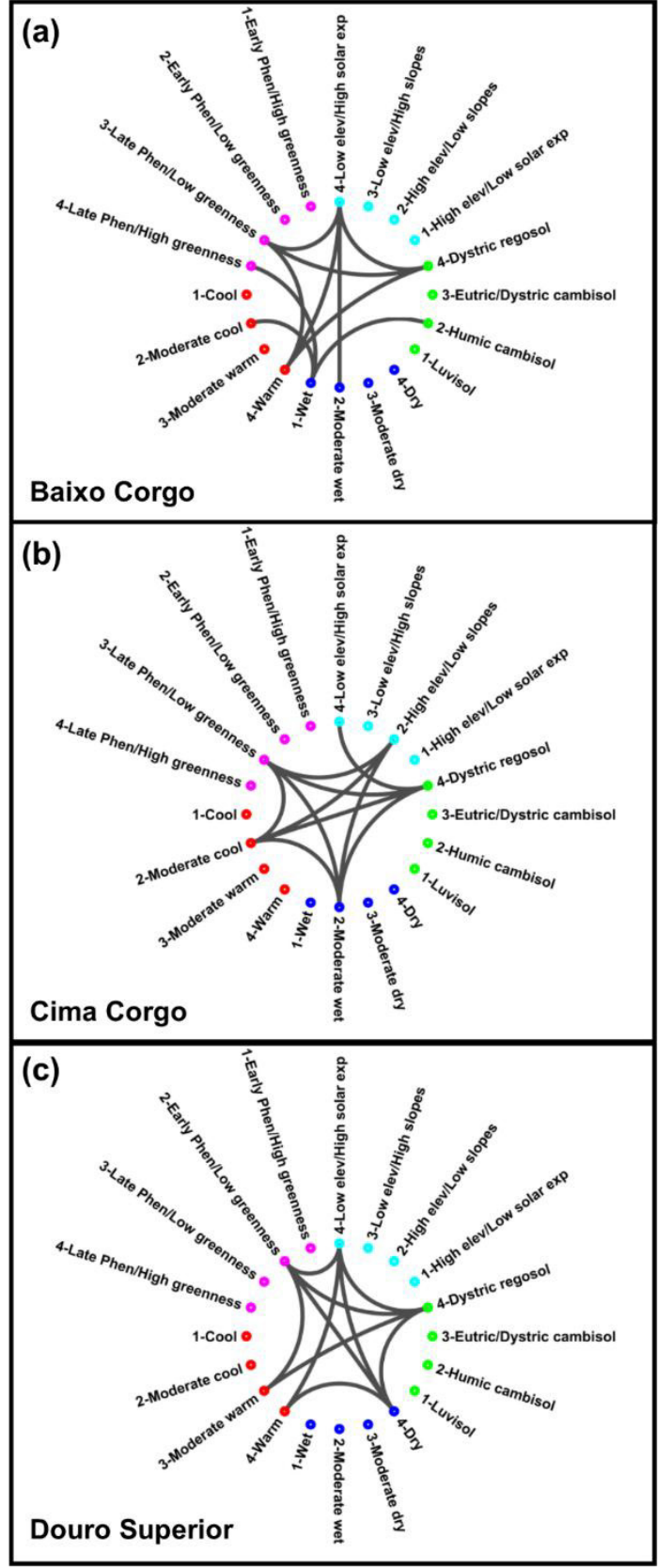

Figure 3 - Chart representing the relationships between clusters of the different terroir elements. Only the highest association inside each sub-region is plotted: (a) Baixo Corgo (BC); (b) Cima Corgo (CC) and (c) Douro Superior (DS).

\section{Discussion and conclusions}

In the current study, homogeneous zones of interest for viticultural activities has been proposed for the DDR, by integrating different terroir elements, using state-ofthe-art high resolution datasets. The integration of all these factors, quantified by a large number of variables, into a high resolution viticultural zoning $(\sim 1 \mathrm{~km})$ in the DDR was not previously performed. The present study thereby significantly improves our understanding of the terroir spatial variability in the DDR.

Overall, four classes of each terroir element (thermal, hydric, soils, topography and vegetation dynamics) have been established, by applying a $k$ - means clustering on the subspace of the leading orthogonal modes. The delimited thermal classes may allow growers to select and grow winegrape varieties based on their optimum thermal requirements. The hydric classes may also assist the selection of suitable rootstocks to improve plant water status. These issues are particularly relevant taking into account the projected climate change impacts for the region, mainly the drying trend over the next decades (Fraga et al. 2016b; Santos et al. 2016). Furthermore, other terroir elements considered herein, such as slope degree, solar exposure, soil type and vegetation greenness, may assist growers in their management activities and vintage planning throughout the year. The inter-connections of the different terroir elements that exist at a given location was innovatively assessed. Although similar methodologies were already applied by previous studies to other winemaking regions, allowing the identification of the existing terroirs, an integration of all these factors was still incipient. These interactions may allow identifying the different environmental processes that account for the winemaking quality potential of the different zones in the DDR.

The multivariate zoning of viticultural terroirs provided in the present study may also be of great importance to policymakers and stakeholders operating in the DDR, acting as an additional decision support tool. In order to promote the usage of this new information, the corresponding dataset is provided in Supporting Information (S1 Appendix). Currently, in this region, a ranking system for vineyard plots is in force, with a classification scheme ranging from the best sites (class A) to the worst (class F) (Instituto dos Vinhos do Douro e Porto - IVDP). This ranking system may also be revised based on the current findings. In addition, taking into account the most recent climate change projections for the region (Fraga et al. 2016b; Santos et al. 2017), this ranking may require substantial adaptations in the future. Lastly, the present study can also be used as an archetypal methodology that can be applied to other winemaking regions in the country and even worldwide.

\section{Acknowledgements}

This work was supported by: the ModelVitiDouro project (PA 53774), funded by the Agricultural and Rural Development Fund (EAFRD) and the Portuguese Government (Measure 4.1 - Cooperation for Innovation PRODER Programme - Rural Development Programme); the INNOVINE\&WINE project (NORTE01-0145-FEDER-000038), co-funded by the European Regional Development Fund through NORTE 2020 Programme; European Investment Funds (FEDER/COMPETE/POCI), POCI-01-0145-FEDER006958, and Portuguese Foundation for Science and Technology (FCT), UID/AGR/04033/2013. The postdoctoral fellowship (SFRH/BPD/119461/2016) awarded to the leading author is also acknowledged. 


\section{References}

Böhm, J., 2010: Portugal vitícola: o grande livro das castas. C. Ferreira, 234 pp.

Costa, R., H. Fraga, P. M. Fernandes, and J. A. Santos, 2017: Implications of future bioclimatic shifts on Portuguese forests. Reg Environ Change, 17, $117-$ 127,10.1007/s10113-016-0980-9

Costantini, E. A. C., R. Lorenzetti, and G. Malorgio, 2016: A multivariate approach for the study of environmental drivers of wine economic structure. Land Use Policy, 57, 5363,10.1016/j.landusepol.2016.05.015

EEA, 2002: CORINE Land Cover update, I\&CLC2000 project, Technical Guidelines.

Fan, Y., H. Li, and G. Miguez-Macho, 2013: Global Patterns of Groundwater Table Depth. Science, N.Y., 339, 940-943,10.1126/science. 1229881

FAO/IIASA/ISRIC/ISSCAS/JRC, 2012: Harmonized World Soil Database (version 1.2). FAO, Rome, Italy and IIASA, Laxenburg, Austria.

Fraga, H., I. Garcia de Cortazar Atauri, A. C. Malheiro, and J. A. Santos, 2016a: Modelling climate change impacts on viticultural yield, phenology and stress conditions in Europe. Glob Chang Biol, 22, 37743788,10.1111/gcb.13382

Fraga, H., A. C. Malheiro, J. Moutinho-Pereira, G. V. Jones, F. Alves, J. G. Pinto, and J. A. Santos, 2014: Very high resolution bioclimatic zoning of Portuguese wine regions: present and future scenarios. Reg Environ Change, 14, 295-306,10.1007/s10113-0130490-y

Fraga, H., J. A. Santos, J. Moutinho-Pereira, C. Carlos, J. Silvestre, J. Eiras-Dias, T. Mota, and A. C. Malheiro, 2016b: Statistical modelling of grapevine phenology in Portuguese wine regions: observed trends and climate change projections. J Agric Sci, 154, 795-811,10.1017/S0021859615000933

Fraga, H., R. Costa, J. Moutinho-Pereira, C. M. Correia, L.-T. Dinis, I. Gonçalves, J. Silvestre, J. Eiras-Dias, A. C. Malheiro, and J. A. Santos, 2015: Modeling Phenology, Water Status, and Yield Components of Three Portuguese Grapevines Using the STICS Crop Model. Am J Enol Vitic, 66, 482491,10.5344/ajev.2015.15031

GTOPO30: Global 30 Arc-Second Elevation (GTOPO30), USGS Products. Data available from the U.S. Geological Survey.,

Hijmans, R. J., S. E. Cameron, J. L. Parra, P. G. Jones, and A. Jarvis, 2005: Very high resolution interpolated climate surfaces for global land areas. Int. J. Clim., 25, 1965-1978,10.1002/joc. 1276

Huete, A., K. Didan, T. Miura, E. P. Rodriguez, X. Gao, and L. G. Ferreira, 2002: Overview of the radiometric and biophysical performance of the MODIS vegetation indices. Remote Sens Environ, 83, 195 213,10.1016/S0034-4257(02)00096-2

IVV, 2015: Vinhos e Aguardentes de Portugal, Anuário 2015. Ministério da Agricultura, do Desenvolvimento Rural e das Pescas: Instituto da Vinha e do Vinho, Lisboa, 236,
Keller, M., 2010: The Science of Grapevines: Anatomy and Physiology. Elsevier, Inc. 400pp,

Morlat, R., and A. Jacquet, 2003: Grapevine root system and soil characteristics in a vineyard maintained long-term with or without interrow sward. Am J Enol Vitic, 54, 1-7,

OIV, 2010: Resolution OIV/VITI 333/2010, Definition of vitivinicultural "TERROIR", Tbilisi, 25th June 2010.

Rivas-Martínez, S., and S. Rivas-Saenz, 2011: Worldwide Bioclimatic Classification System. Phytosociological Research Center, Spain, http://www.globalbioclimatics.org.

Santos, J. A., R. Costa, and H. Fraga, 2017: Climate change impacts on thermal growing conditions of main fruit species in Portugal. Clim Change, 140, 273-286,10.1007/s10584-016-1835-6

Santos, J. A., M. Belo-Pereira, H. Fraga, and J. G. Pinto, 2016: Understanding climate change projections for precipitation over western Europe with a weather typing approach. J Geophys Res-Atmos, 121, 1170-1189,10.1002/2015JD024399

Tonietto, J., 1999: Les macroclimats viticoles mondiaux et l'influence du mésoclimat sur la typicité de la Syrah et du Muscat de Hambourg dans le sud de la France: méthodologie de caractérisation. $\mathrm{PhD}$ Dissertation, 233p, Ecole Nationale Supérieure Agronomique, Montpellier, France.

Tonietto, J., and A. Carbonneau, 2004: A multicriteria climatic classification system for grape-growing regions worldwide. Agric For Meteorol, 124, 8197,10.1016/j.agrformet.2003.06.001

Winkler, A. J., 1974: General viticulture. University of California Press.

Yau, I. H., J. R. Davenport, and R. A. Rupp, 2013: Characterizing Inland Pacific Northwest American Viticultural Areas with Geospatial Data. Plos One, 8,10.1371/journal.pone.0061994 